\title{
COMO EXPERIÊNCIAS NO EXTERIOR AGREGAM NA CARREIRA DO PROFISSIONAL DE ADMINISTRAÇÃO
}

\section{Emannuely Ostroswski Pereira da Silva ${ }^{a}$ \\ Maria D'Lourdes Rotermund ${ }^{\mathrm{b}}$}

aBacharela em Administração. Centro Universitário Metodista. emannuelyops@gmail.com.

${ }^{\mathrm{b}}$ Mestre em Administração. Centro Universitário Metodista. maria.rotermund@metodistadosul.edu.br.

\section{RESUMO}

O mercado de trabalho atual conta com um novo modelo de profissional disponível: os nômades globais. São indivíduos que saem do seu país de origem para conhecer e absorver conhecimentos e costumes nas mais variadas culturas e retornam ao seu país com essa bagagem de conhecimento. Desta forma, as organizações precisam estar preparadas para receber e absorver o máximo de conhecimento possível deste profissional. Este estudo tem como objetivo identificar como as experiências no exterior agregam na carreira do profissional de administração. A metodologia utilizada é de natureza exploratória, com abordagem qualitativa. Foram sujeitos da pesquisa nove acadêmicos e bacharéis em administração que, em algum momento de sua vida, passaram por experiências fora do seu país de origem, estes localizados no estado do Rio Grande do Sul. A técnica de coleta de dados foi entrevista com roteiro semiestruturado. A técnica de análise dos dados foi interpretativa, com comparações com o referencial teórico. A conclusão deste estudo é que para ser considerado um nômade global o indivíduo deve se sentir desta forma e buscar desenvolver suas aptidões através das experiências adquiridas em outros países que não o seu de origem. Há espaço para que os profissionais desenvolvam suas tarefas com base em suas experiências em outros países, porém as empresas ainda precisam se abrir para incentivar o profissional a 
aplicar seus conhecimentos adquiridos fora, no cotidiano das atividades da organização.

PALAVRAS-CHAVE: Nômades globais. Desenvolvimento de pessoas. Carreira. Perfis geracionais.

\section{HOW EXPERIENCES ABROAD ADD IN THE CAREER'S PROFESSIONAL ADMINISTRATION}

\section{ABSTRACT}

The current job market has a new model of professional available: the global nomads. They are individuals who leave their country of origin to know and absorb knowledge and customs in the most varied cultures and return to their country with this baggage of knowledge. In this way, organizations need to be prepared to receive and absorb as much knowledge as possible from this professional. This study aims to identify how the experiences abroad add to the career of the management professional. The methodology used is exploratory in nature, with a qualitative approach. Nine academic or bachelors in administration who had, at some point in their life, passed through experiences outside their country of origin, these located in the state of Rio Grande do Sul. The technique of data collection was interview with script semistructured. The technique of analyzing the answers is interpretive, with comparisons of the data searched with the theoretical reference set forth in the study. The conclusion of this study is that to be considered a global nomad the individual should feel this way and seek to develop their skills through experiences acquired in countries other than their origin. There is room for professionals to develop their tasks based on their experiences in other countries, but companies still need to be more open to encourage the professional to apply their knowledge acquired outside the daily activities of the organization.

KEYWORDS: Global nomads. Developing people. Career. Generational profiles.

\section{INTRODUÇÃO}

Em uma sociedade voltada para a comunicação e informação onde os profissionais estão cada vez mais conectados com o mundo, se faz possível à adaptação de variados perfis de colaboradores que buscam se adequar a estas mudanças 
tecnológicas e estarem conectados em todos os momentos. Com o acesso à internet se tornou mais fácil viajar e conhecer outras culturas, com esta facilidade surge o profissional nômade global, são jovens com aspirações distintas de carreira, e desejos imediatos que estão entrando no mercado de trabalho em busca do seu espaço. São caracterizados nômades globais, pois conhecem diferentes culturas e diferentes países não apenas o seu de origem e adquirem uma bagagem de conhecimento diferente do que vem proposto em cursos, faculdades e que é colocado em currículos (MATTEWMAN, 2012; IANNI, 2006).

Dessa forma a carreira do profissional de administração deve se enquadrar nestes novos rumos que a globalização está ofertando ao mercado de trabalho. As mudanças e melhorias que as organizações desejam, definem o caminho que a gestão de pessoas vai seguir e o tipo de profissional que buscam para atuar na mesma. Há uma demanda por colaboradores "super-heróis", que nada mais é do que a retenção de talentos já desenvolvidos a fim de ampliar os conhecimentos da empresa e melhorar o desenvolvimento das tarefas, mas não basta apenas reter este talento, é necessário mantê-lo na empresa (FISCHER; DUTRA; AMORIM, 2009).

Com o surgimento do profissional nômade global e sua disponibilidade no mercado de trabalho, o setor de recursos humanos precisa se adaptar as necessidades das empresas, e buscar conhecer, reter e absorver o máximo possível destes talentos que estão disponíveis no mercado. Em muitas situações as qualidades e competências do profissional não estão descritas no currículo, mas nas experiências e competências desenvolvidas através das vivências que nem sempre são profissionais ou acadêmicas. Mattewmann (2012) expõe o novo perfil de profissional, os nômades globais, que possuem traços comportamentais distintos, fazendo-se necessária a análise deste indivíduo que vem para o mercado de trabalho com 
aspirações e desejos imediatos de carreira (FRANÇA, 2011; MATTEWMANN, 2012).

Buscar o total aproveitamento das experiências deste profissional para a organização é fundamental no processo de construção de carreira. Saber absorver tudo o que o nômade tem que a oferecer pode se tornar um diferencial tanto para a empresa, como para o profissional, obter conhecimento de como situações são contornadas e resolvidas em um país diferente, pode abrir portas para o crescimento e aperfeiçoamento de variadas práticas de mercado. Desta forma o estudo propôs verificar como as experiências no exterior agregam na carreira do profissional de administração.

\section{REFERENCIAL TEÓRICO}

Chiavenato (2010, p. 227) aborda o sistema de administração de carreiras como "sequência de posições e atividades desenvolvidas por uma pessoa ao longo do tempo em uma organização", salientando que o crescimento dentro da organização pode ser tanto vertical como horizontalmente. Mas como as empresas estão cada vez mais enxutas abre-se cada vez mais oportunidades no âmbito horizontal do cargo em que o profissional ocupa onde a vaga oferecida dispõe do mesmo nível já ocupado, com o diferencial de ser mais complexo ou com especialidades diferentes. Proporcionar ao colaborador um bom relacionamento com suas tarefas, visando o aumento da produtividade, requer da organização estratégias voltadas para a melhoria da qualidade de vida do profissional, buscando o equilíbrio das necessidades e anseios, tanto do colaborador, quanto da empresa (CHIAVENATO, 2010; DUTRA, 2009)

Robbins (2005) cita quatro pontos importantes que mostram que a empresa pode fornecer subsídios para o desenvolvimento do profissional, para que ele possa se adequar as necessidades da empresa e assim ser capaz de participar do sistema de administração de carreiras, conforme exposto no Quadro 1. 
Quadro 1 - Apoio necessário para o desenvolvimento de carreira

\begin{tabular}{|c|c|}
\hline $\begin{array}{c}\text { Subsídios para o de- } \\
\text { senvolvimento }\end{array}$ & Descrição \\
\hline $\begin{array}{c}\text { Comunicação clara } \\
\text { das metas e estraté- } \\
\text { gias da organização }\end{array}$ & $\begin{array}{c}\text { Assim o colaborador é capaz de se planejar } \\
\text { a longo prazo, encaixando suas necessidades } \\
\text { pessoais as da empresa; }\end{array}$ \\
\hline $\begin{array}{c}\text { Criação de oportuni- } \\
\text { dades de crescimento } \\
\text { dentro da organização }\end{array}$ & $\begin{array}{c}\text { O colaborador deve ter oportunidade de } \\
\text { desfrutar experiências novas, interessante } \\
\text { e profissionalmente desafiadoras dentro da } \\
\text { organização; }\end{array}$ \\
\hline $\begin{array}{c}\text { Assistência financeira } \\
\text { É interessante para a empresa e para o } \\
\text { colaborador que a organização invista em } \\
\text { cursos e treinamentos necessários para o } \\
\text { desenvolvimento do colaborador dentro da } \\
\text { empresa motivando o colaborador a estudar e } \\
\text { a desenvolver seus pontos positivos; }\end{array}$ \\
$\begin{array}{c}\text { Disponibilizar tem- } \\
\text { po necessário para } \\
\text { o aprendizado dos } \\
\text { colaboradores }\end{array}$ & $\begin{array}{c}\text { A empresa deve conceder tempo remunerado } \\
\text { aos colaboradores para que eles façam seus } \\
\text { cursos e treinamentos para que assim possam } \\
\text { desenvolver suas habilidades, capacidades e } \\
\text { conhecimentos. }\end{array}$ \\
\hline
\end{tabular}

Fonte: Adaptado de Robbins (2005, p.460)

O sistema de carreira também pode ser baseado nas competências, que são comportamentos advindos de influências ambientais e profissionais, que agregam valor econômico e social, para os colaboradores e a organização, capazes de mobilizar, interagir, transferir conhecimentos e habilidades entre grupos de pessoas, dentro e fora da organização. Em cada pessoa as competências afloram de formas diferentes a partir de características inatas e adquiridas, Chiavenato (2010) mostra em forma de fluxo na Figura 1 como se formam as competências. 
Figura 1 - Formação de Competências

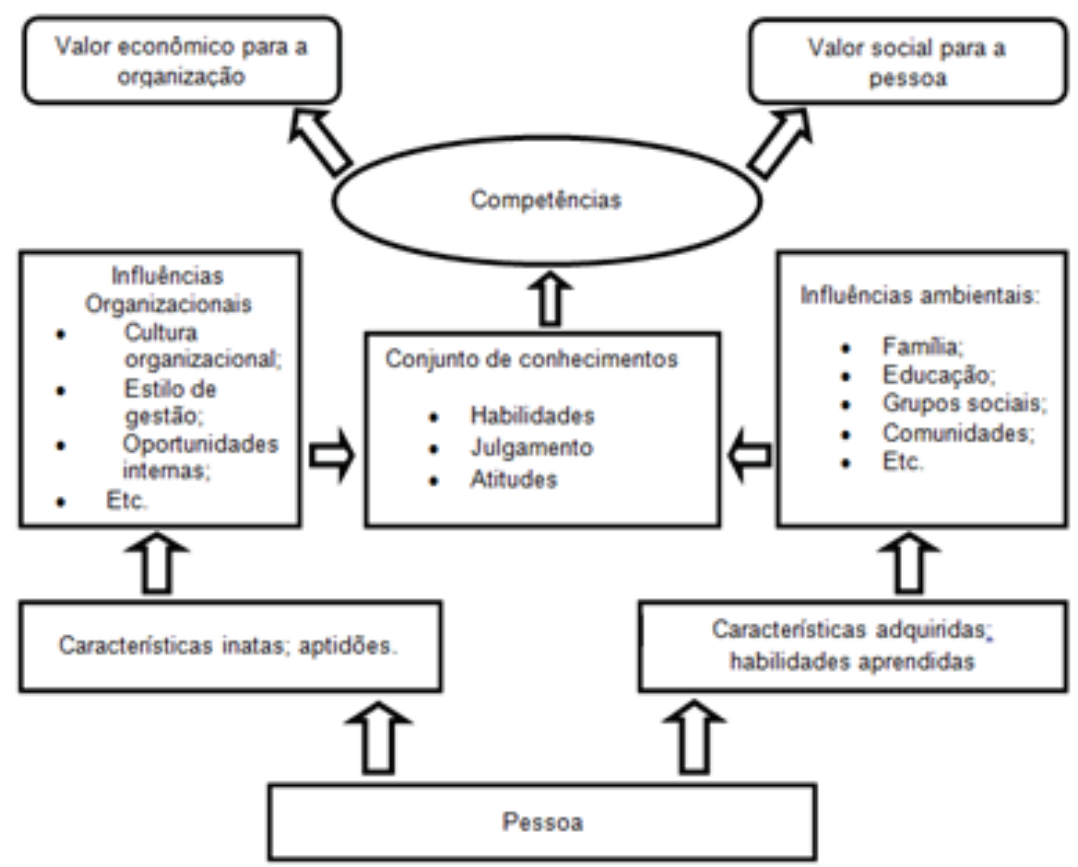

Fonte: Chiavenato (2010, p. 142).

O sistema de recompensas por competências prevê valorizar o profissional com base no conjunto de qualificações que ele possui e a forma com que desempenha seu papel na organização. Diferentes profissionais podem entregar determinadas demandas de variadas maneiras, portanto cada um com seu grau de excelência, estas seriam as competências destinadas a cada um. Valorizar e encaixar os diferenciais de cada colaborador com suas funções faz com que o profissional transfira para a organização seu aprendizado e assim é capaz de capacitar a organização para enfrentar novos desafios. (DUTRA, 2009).

O sistema de organização de carreira, segundo Silva (2011) e Tolfo (2011), sofreu muitas mudanças no decorrer dos anos 
se tornando flexível, heterogêneo e complexo para as empresas e os colaboradores. Desta forma podem ocorrer mudanças em todos os âmbitos do trabalho, se fazendo interessante às empresas conhecerem o perfil de cada profissional para aloca-lo em funções que o profissional se sinta confortável e que possa colaborar cada vez mais em suas atividades. Na Figura 2 Mattewman (2012) enumera as estratégias de mudança necessárias na gestão de pessoas.

Figura 2 - "Estratégias de mudança para o capital humano"

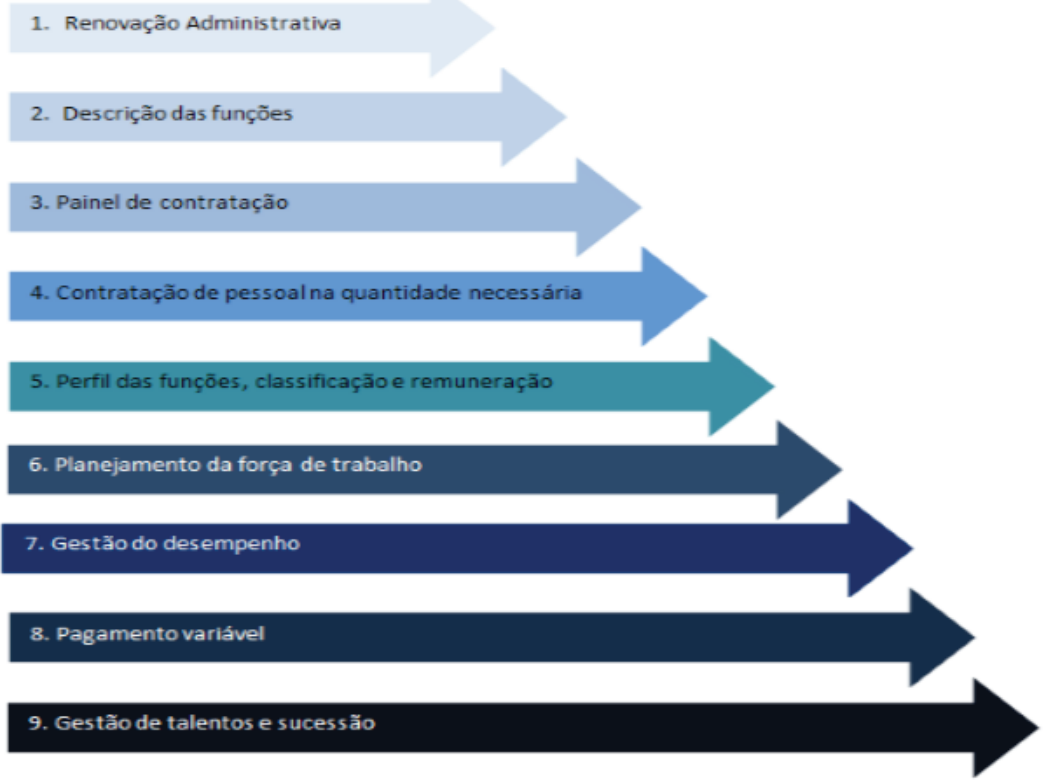

Fonte: Mattewman (2012, p. 151).

Aflora no setor de recrutamento e seleção a busca por profissionais qualificados que se adaptem as necessidades internas e externas da organização, sabendo se posicionar em meio a flexibilidade exigida pelas organizações e as funções a serem desempenhadas é o desafio atual das organizações que buscam 
crescimento contínuo aliado a profissionais dispostos a disponibilizar a sua carga de conhecimento para o aperfeiçoamento pessoal e da organização. As mudanças proporcionadas pela globalização acelerada trouxeram desafios para a economia das organizações, e para a Gestão de Pessoas, que precisa se adaptar ao desenvolvimento contínuo do mercado de trabalho em conjunto com a diversidade de colaboradores e perfis disponíveis (FISCHER, 2009; DUTRA, 2009; AMORIM, 2009).

Assim, neste novo contexto global de mudança e disseminação de informações em curto prazo, o interesse e entusiasmo que os jovens apresentam deve ser um aliado das organizações que precisam de atitudes transparentes perante estes colaboradores, que são os clientes internos da empresa, que anseiam por atenção e clareza de informação. Portanto, um importante fator a ser analisado é a comunicação clara das funções que cada colaborador desempenha dentro da empresa, assim como deixar explícito a quem devem se reportar, demonstrando preocupação da organização em relação ao desempenho do profissional e da certeza que ele estará bem amparado. (MATTEWMAN, 2012).

A cada ano o número de países visitados por indivíduos com menos de 30 anos tem aumentado exponencialmente, o número de pessoas que falam dois ou mais idiomas tem aumentando a cada dia, e o inglês tornou-se o idioma dominante entre as novas gerações. É visível a quantidade de mudanças que vem ocorrendo no cotidiano dos jovens profissionais, que investem em ensino direcionado para a globalização da comunicação. O que vem facilitando as viagens de lazer e a trabalho, fazendo com que a cada dia mais os viajantes desenvolvam sua maneira de socializar, sendo capazes de se adaptar a diferentes culturas e formas de ser e de se relacionar (MATTEWMAN, 2012). 
Mattewman (2012, p 66) relata que os nômades globais "buscam uma promessa de trabalho desafiador compensado com um estilo de vida ativo e dinâmico de pessoas com as mesmas ideias", buscam um estilo de vida mais ativo do que do local onde nasceram e cresceram e onde acreditam ter um ritmo lento de crescimento e desenvolvimento. Há um fluxo crescente de talentos que saem de seu país de origem para se aventurar em uma cultura diferente para obter o que não encontram no ambiente em que foram criados. Buscam o conhecimento na prática, atrelado a experiências desafiadoras para sua vida pessoal e carreira profissional (MATTEWMAN, 2012).

Segundo Oliveira (2010) os nômades globais valorizam as experiências internacionais, pois eles não possuem realmente um vínculo com sua própria cultura. Querem sempre ser reconhecidos por seu trabalho e resultados, por vezes não se preocupam demasiadamente com hierarquia, e buscam acima de tudo carreiras brilhantes. "Não é de admirar que os gestores, em sua maioria, sejam resistentes quando se relacionam com esses jovens" (OLIVEIRA, 2010, p 141) a possibilidade de que alguém bem mais jovem possa desenvolver mais rápido e melhor as habilidades necessárias dentro da empresa provoca a reação de ameaça aos líderes. Esta forma de ser dos nômades globais teve sua origem nas próprias expectativas dos pais, durante anos os pais se empenharam da educação de seus filhos, criando muitas vezes diferenciais que pudessem posiciona-los de forma vantajosa nas empresas perante os colegas.

\section{METODOLOGIA}

$\mathrm{Na}$ busca por ampliar os conhecimentos desenvolvidos nesta pesquisa, e atender os objetivos estabelecidos, o estudo se desenvolveu com base em uma pesquisa exploratória. De acordo com Cervo e Bervian (2002) a pesquisa exploratória 
tem como foco principal fazer com que certos fenômenos não presenciados anteriormente se tornem presentes e reconhecidos pela sociedade, sendo possível a disseminação e conhecimento do determinado assunto pouco explorado.

Em relação à abordagem do problema, a pesquisa é de natureza qualitativa, onde a pesquisa se torna interpretativa, assim o pesquisador se envolve com a experiência intensa dos entrevistados, fazendo-se necessário uma conexão com experiências e vivências passadas para que se possa enriquecer a pesquisa, fortalecendo os argumentos apresentados e demonstrando a abrangência do tema em questão. A pesquisa qualitativa busca uma seleção intencional dos entrevistados com base no estudo que foi proposto inicialmente, tornando a coleta de dados direcionada apenas ao que foi proposto (CRESWELL, 2010).

Os critérios para escolha dos acadêmicos de administração foi trabalhar em sua área de futura formação, e que assim sejam capazes de utilizar as experiências obtidas no exterior em seu dia a dia profissional. Os bacharéis da área em questão, devem estar em atividade em sua formação acadêmica e utilizarem também suas experiências em outros países em seu ambiente profissional, podendo agregar seus conhecimentos e a forma com que foram absorvidos neste estudo.

Foram sujeitos do estudo nove acadêmicos de administração e bacharéis em administração, que tivessem em algum momento de sua vida realizado a vivência no exterior. Para que fosse possível a colaboração para a pesquisa, além de se encaixar nos requisitos, a coleta de dados foi fundamentada na técnica "bola de neve", onde o primeiro passo para o inicio das entrevistas é localizar o indivíduo inicial pertencente ao grupo de estudo. Assim, a coleta de dados se desenvolveu por indivíduos com perfis semelhantes, que foram sendo indicados pelos sujeitos já entrevistados que se encaixavam nos 
objetivos propostos inicialmente, buscando a veracidade dos fatos apresentados (DEWES, 2013).

O estudo teve como técnica entrevista em profundidade conforme Apêndice A, com roteiro semiestruturado. Uma entrevista consiste em uma investigação para coleta de dados, se tornando muitas vezes superior a outros sistemas sofisticados de coleta de dados. Um roteiro semiestruturado baseia-se em uma conversação aonde as perguntas são abertas podendo ser respondidas dentro de um diálogo informal. Com isto a coleta através da técnica "bola de neve" não teve continuidade, pois as respostas foram se repetindo entre si, um exemplo seriam as perguntas "quais as semelhanças entre as culturas visitadas e a de origem?" e "diferenças pré e pós viagem" onde diversos entrevistados responderam de formas semelhantes (MARCONI; LAKATOS, 2010).

O estudo teve como base a interpretação dos dados coletados, que segundo Cervo e Bervian (2002) consiste em leitura, análise, reflexão, diferenciação, comparação e apontamentos referentes aos dados coletados. Sendo de extrema importância para o estudo, demandando tempo e esforço do pesquisador.

\section{ANÁLISE E DISCUSSÃO DOS RESULTADOS}

Em relação a faixa etária dos entrevistados, para melhor visualização, foram divididos em três faixas: até 34 anos de idade coposta por sete dos entrevistados, Mattewman (2012) relata que indivíduos nascidos a partir de 1983 são considerados pertencentes a Geração Y e em geral possuem senso social inestimado, são confiantes e criativos; de 34 a 52 anos onde um dos entrevistados se enquadrou, Oliveira (2010) analisa estes indivíduos como pertencentes da Geração X, são confiantes em si mesmo e em geral desconfiam das autoridades como um todo; e acima de 52 anos, caracterizado como da geração de Baby Boomers conforme Oliveira (2010), com apenas um 
entrevistado, esta geração tem por característica a ordem e a obediência.

Em relação a questionamentos referentes a renda, foi perguntado quanto cada um deles gastava em porcentagem de sua renda mensal com custos fixos e quanto por cento era guardado, onde três dos entrevistados relataram que gastam $80 \%$ da renda em contas fixas, dois dos entrevistados dizem ser $100 \%$ de sua renda em contas fixas, um dos entrevistados, apontou $40 \%$ de sua renda; um dos entrevistados $60 \%$ da renda; um dos entrevistados $70 \%$ da renda e um $95 \%$ da renda é destinada para contas fixas.

Outro tópico abordado na entrevista foi o tempo de planejamento de cada um em relação a viagem, conforme o Quadro 2.

Quadro 2 - Tempo de Planejamento versus Tempo de Viagem

\begin{tabular}{|c|c|c|}
\hline Entrevistado & Tempo de Planejamento & Tempo de Viagem \\
\hline E1 & 7 meses & 15 dias \\
\hline E2 & 1 ano & 1 ano e 6 meses \\
\hline E3 & 1 ano & 1 ano e 6 meses \\
\hline E4 & 6 meses & 1 ano \\
\hline E5 & 3 meses & 10 dias \\
\hline E6 & 5 meses & 15 dias \\
\hline E7 & 4 meses & 15 dias \\
\hline E8 & 3 meses & 2 anos e 6 meses \\
\hline E9 & 4 meses & \\
\hline
\end{tabular}

Fonte: Elaborado pela autora, 2017.

Sobre o tema, Robbins (2005) e Chiavenato (2010) destacam a necessidade do colaborador buscar organizar sua carreira de forma que seja melhor aproveitada por ele e pela empresa, desta forma funciona o desenvolvimento da vida do 
indivíduo como um todo. Os entrevistados E1, E6 e E8 relataram o mesmo período de tempo em suas experiências, porém o período de planejamento de ambos não se assemelha, 7 meses, 5 meses e 3 meses respectivamente, desta forma também ocorre com os entrevistados E2, E3, E7 e E9 onde o período de estadia no país foi acima de 1 ano, e seus planejamentos oscilam entre 1 ano, sendo os entrevistados E2 e E3, e 4 meses os entrevistados E7 e E9.

Dutra (2009) ressalta como as aptidões de cada líder podem impactar no desenvolvimento das atividades e a forma com que os colaboradores serão dentro da organização, assim como o tempo e a forma de planejamento podem influenciar no decorrer da viagem, esta organização e administração dos recursos disponíveis é uma aptidão que pode ser um diferencial para um bom líder ou colaborador.

O custo de vida no país visitado e no país de origem estão expressos no Quadro 3 onde os entrevistados, E2 e E3 dizem que o país visitado possuí um baixo custo de vida em comparação ao Brasil, e em relação a remuneração recebida, onde o valor pago faz jus ao trabalho desempenhado, sem contar que não há a necessidade de seguro para casa, para o carro, pois o país é seguro, e conta com uma boa estrutura vinda do governo. Os outros entrevistados acreditam que o país possuí um alto custo de vida em comparação com o Brasil, porém todos foram categóricos em dizer que a segurança, transporte público, saúde são de qualidade, o que supriria os valores mais elevados. 
Quadro 3 - Semelhanças entre o país visitado e o Brasil: Custo de vida

\begin{tabular}{|c|c|}
\hline \multicolumn{2}{|c|}{ Custo de vida } \\
\hline E2 e E3 & $\begin{array}{c}\text { O custo de vida baixo comparado aos padrões de remu- } \\
\text { neração brasileira, por mais que os custos sejam mais } \\
\text { elevados a remuneração é justa pelo trabalho desempe- } \\
\text { nhado. }\end{array}$ \\
\hline $\begin{array}{c}\text { E1, E4, E5, } \\
\text { E6, E7, E8 } \\
\text { e E9 }\end{array}$ & $\begin{array}{c}\text { Custo de vida alto, porém a segurança, transporte e siste- } \\
\text { ma de saúde de qualidade, com salários compatíveis aos } \\
\text { preços dos produtos e serviços disponíveis no país. }\end{array}$ \\
\hline
\end{tabular}

Fonte: Elaborado pela autora, 2017.

No Quadro 4 seguem as respostas referentes às diferenças entre o país visitado e o país de origem do entrevistado em relação ao ambiente. Os entrevistados destacaram a qualidade do transporte público, as questões relacionadas à segurança e saúde e todas as ferramentas que o país possuía para assegurar a integridade dos visitantes e cidadãos.

Mattewman (2012) relata a necessidade que cada indivíduo possui de buscar por qualidade de vida, através de mudanças de países ou mudanças de hábitos. Muitos profissionais querem a melhoria da carreira e o desenvolvimento de suas qualidades, e migram em busca destas melhorias em relação às empresas e a contratação de pessoal. Acrescentar a experiência no exterior ao currículo também pode ser um diferencial, e o autor relata a necessidade do reconhecimento das empresas em função da vivência que cada nômade global teve em outros países, e a forma que pode agregar para a empresa. 
Quadro 4 - Diferenças entre o país visitado e o Brasil: Ambiente

\section{Ambiente}

“Tudo é muito limpo e organizado, baixa inflação entre um ano e outro assim como o índice de assaltos e roubos, o transporte público é de qualidade."

"Todo o pais é muito limpo e seguro, tem muitos policiais nas ruas, e as leis funcionam, quando acontece algum crime as pessoas pagam por ele, os ônibus e trens são muito bem cuidados e dificilmente lotavam."

E6

“Tudo é muito organizado, o transporte público é distribuído de forma igualitária, sem ficar lotado."

"Todas as cidades eram limpas, e haviam muitos policiais. Todos os cidadãos respeitavam os ciclistas, esperando uma distância segura para ultrapassar com os carros."

“Tudo muito organizado, transporte público de qualidade, porém há crimes como em qualquer cidade mas a fiscalização e a penalização funcionam."

Fonte: Elaborado pela autora, 2017.

As respostas dos entrevistados com relação às pessoas e as semelhanças e diferenças do país visitado e do país de origem estão no Quadro 5, onde a maioria os entrevistados citaram o grande número de estrangeiros de todas as nacionalidades, outras características foram mencionadas, como acolhedoras, atenciosas, educados.

O entrevistado E4 que morou na Itália, e dividiu seu quarto com colegas de outras nacionalidades, mencionou a diferença entre as culturas e a dificuldade de se adaptar as manias e costumes de pessoas que vem de países diferentes. Mattewman (2012) relata a necessidade de uma abordagem neutra quando se trata de multiculturas inseridas em um mesmo espaço, sendo necessária a adaptação de costumes e manias para que possa ter foco no que pode agregar para o crescimento de ambos.

ReMAS • Revista Metodista de Administração do Sul, v. 2, N. 1, 2017 
Quadro 5 - Semelhanças entre o país visitado e o Brasil: Pessoas

\begin{tabular}{|c|c|}
\hline \multicolumn{2}{|r|}{ Pessoas } \\
\hline E1 & $\begin{array}{c}\text { "Tem pessoas de todas as nacionalidades, são acolhedoras e aten- } \\
\text { ciosas com os turistas." }\end{array}$ \\
\hline E2 & $\begin{array}{l}\text { "Não há o costume de julgar as pessoas sem conhecê-las ou sem } \\
\text { saber o que está acontecendo, são muito acolhedores, há muitos } \\
\text { estrangeiros, o que acaba sendo mais difícil caracterizar os "cana- } \\
\text { denses", pois há uma grande mistura dos povos." }\end{array}$ \\
\hline E3 & $\begin{array}{c}\text { "Se vestem da forma que se sentem bem e não reparam as roupas } \\
\text { uns dos outros. Tem estrangeiros de todas as nacionalidades tan- } \\
\text { to trabalhando quanto estudando." }\end{array}$ \\
\hline E4 & $\begin{array}{l}\text { "São pouco acolhedoras e possuem manias e costumes diferen- } \\
\text { tes dos brasileiros, todos se vestem na moda, e não julgam as } \\
\text { pessoas seja pela forma de se vestir, de ser e de agir. Haviam } \\
\text { pessoas de todas as nacionalidades." }\end{array}$ \\
\hline E5 & $\begin{array}{c}\text { "Tinham muitos turistas de todas as nacionalidades. Os morado- } \\
\text { res locais despertavam muita "felicidade"." }\end{array}$ \\
\hline E7 & $\begin{array}{c}\text { "Todos muito acolhedores tratam os estrangeiros muito bem, e } \\
\text { não julgam ninguém sem conhecer, tem o estilo muito casual, se } \\
\text { vestem de qualquer forma, sem se importar com o que os outros } \\
\text { vão pensar." }\end{array}$ \\
\hline E8 & $\begin{array}{c}\text { "Todos muito educados e solícitos, gostam de turistas, querem } \\
\text { sempre ajudar e participar dos passeios." }\end{array}$ \\
\hline E9 & $\begin{array}{l}\text { "Levam a vida de uma forma muito frenética, sempre trabalhan- } \\
\text { do e estudando, não são apegados a família, apenas se reúnem } \\
\text { em poucas datas, só quando é muito necessário." }\end{array}$ \\
\hline
\end{tabular}

Fonte: Elaborado pela autora, 2017

Em relação às diferenças que foram percebidas nos entrevistados após retornarem de suas experiências, expostas no Quadro 6, os entrevistados E1 e E4 relataram que vão arriscar falar outro idioma em próximas experiências; E2 e E3 que moram no Canadá, dizem arriscar oportunidades em outros países caso não possam ficar residindo no país; E2, E4 
e E8 buscam a qualidade de vida que tem e tiveram em suas experiências, e desta forma buscam por opções que possam garantir qualidade em relação à segurança, saúde, educação e moradia, dentro outros.

Os entrevistados E4, E5, E6 e E7 possuem a mesma opinião em relação a diversidade e vida em sociedade, ambos acreditam ser mais tolerantes em situações que passariam despercebidas antes das experiências, E2, E3, E4, E5, E6 e E7 relatam que buscam não julgar as pessoas e situações sem conhece-las, pois puderam observar como os indivíduos de outras culturas reagem de forma diferente da apresentada pelos brasileiros em muitas situações. Quadro 6 na página seguinte.

A forma de perceber o mundo e suas variadas facetas após a viagem teve alteração em todos os entrevistados que passaram a ter uma visão diferenciada de situações que antes passavam despercebidas. Mattewman (2012) descreve as experiências no exterior e a globalização como a melhor forma de socializar e aprender a se adaptar a diferentes culturas e formas de pensar, e assim forma se tornar um indivíduo global, como foi relatado pelo entrevistado E7 que após suas experiências no exterior se considera com muito orgulho um "cidadão da humanidade".

Quando questionados sobre sua visão em relação às experiências no exterior e a forma com que o mercado de trabalho brasileiro absorve essa bagagem, todos foram categóricos em relatar a importância das organizações disponibilizarem espaço e serem flexíveis para que os conhecimentos adquiridos nas viagens possam ser disseminados e aproveitados nas tarefas desempenhadas na empresa, por mais que a experiência tenha sido de trabalho e estudo ou para passeio, pois toda a forma de conhecimento é válida. Desta forma também Mattewman (2012) relata a necessidade de um ambiente de trabalho que dê espaço para o colaborador criar e aperfeiçoar cada atividade a sua maneira, da forma que julga ser a mais adequada para si e para o bom desenvolvimento das suas tarefas. 
Quadro 6 - Diferenças percebidas pós viagem

\begin{tabular}{|c|c|}
\hline E1 & $\begin{array}{l}\text { - Arriscar o idioma: inglês. } \\
\text { - Curiosidade em conhecer novos lugares. }\end{array}$ \\
\hline E2 & $\begin{array}{l}\text { - Arriscar oportunidades em países diferentes. } \\
\text { - } \text { - Busicação aos estudos. } \\
\text { - Não julgar as pessoas sem ter conhecimento do que o in- } \\
\text { divíduo precisa. }\end{array}$ \\
\hline E3 & $\begin{array}{l}\text { - Arriscar oportunidades em países diferentes. } \\
\text { - } \text { - Irá cobrar mais dos governantes em relação a segurança, } \\
\text { - } \quad \text { saúde, transporte público etc. } \\
\text { - }\end{array}$ \\
\hline $\mathrm{E} 4$ & $\begin{array}{l}\text { - Arriscar falar mais em outro idioma. } \\
\text { - Aprendeu a lidar com as diferenças. } \\
\text { - } \text {-Gestão por diversidade". } \\
\text { - Selocar no lugar dos indivíduos antes de julgar. }\end{array}$ \\
\hline E5 & $\begin{array}{l}\text { - } \quad \text { Buscar agir da forma mais adequada com cada pessoa. } \\
\text { - } \quad \text { Eño julgar sem conhecer. } \\
\text { entre si. }\end{array}$ \\
\hline E6 & $\begin{array}{l}\text { - Entendeu que cada pessoa tem uma forma de ser e agir, } \\
\text { que é característica de cada indivíduo, e não julgar sem } \\
\text { ter conhecimento prévio. } \\
\text { - Status que a experiência lhe proporcionou. }\end{array}$ \\
\hline E7 & $\begin{array}{l}\text { - Se colocar no lugar das pessoas. } \\
\text { - Evitar julgar sem conhecer. } \\
\text { - Paciência com a convivência em grupo. } \\
\text { - Não se preocupar tanto com a aparência. }\end{array}$ \\
\hline E8 & $\begin{array}{l}\text { - Mudança de pensamento em relação aos serviços dispo- } \\
\text { nibilizado pela sociedade aumentando a exigibilidade e } \\
\text { criticidade. }\end{array}$ \\
\hline E9 & $\begin{array}{l}\text { - Conhecimento do idioma. } \\
\text { - Experiência em ter vivido em uma cultura totalmente di- } \\
\text { ferente. }\end{array}$ \\
\hline
\end{tabular}

Fonte: Elaborado pela autora, 2017. 
Foi questionado se os entrevistados se consideram ou não nômades globais, onde, dos nove entrevistados, seis acreditam ser nômades globais e três acreditam não se encaixarem neste perfil. Cabe salientar que segundo Mattewman (2012) nômade global é o individuo que saí do seu país de origem, conhece novas culturas e vivencia na prática os costumes e manias daquele povo, e posterior a isto, retorna para seu país de origem com esta bagagem de conhecimento a fim de implantar melhorias advindas desta experiência em seu cotidiano. Para responder a este questionamento, foi explicado aos entrevistados a definição de nômade global, e questionado em relação a sua percepção sobre seu comportamento e esta definição.

Os três entrevistados que não se consideram nômades globais, foram os que fizeram viagens apenas para passeio, e acreditam que não se enquadram nesta definição, pois foram apenas como turistas, e não com o interesse de absorver a cultura local, mas sim de conhecer e desfrutar, e por mais que tivessem bons exemplos que poderiam ser seguidos, estes ensinamentos ficaram apenas no período da viagem, e por questão de costume e cultura não seriam capazes de aplicar no dia a dia. Cabe salientar que todos os entrevistados ressaltaram pontos positivos em suas experiências, e relataram melhora em questões de idioma e gestão da diversidade de pessoas.

Os seis entrevistados que se denominaram como nômades globais, são os que ficaram mais tempo em suas experiências fora do país e que trabalharam e estudaram fora além de passear e desfrutar do país, todos foram categóricos em afirmar que sentem orgulho desta denominação (que não era de conhecimento de nenhum dos entrevistados) e que não seria possível passar pela experiência em outra cultura e outro povo sem ser capaz de se influenciar e aprender, e desta forma aplicar e buscar melhorar tudo que for possível para ser um profissional e indivíduo melhor. 


\section{CONSIDERAÇÕES FINAIS}

Este estudo teve como objetivo central identificar como as experiências no exterior agregam na carreira do profissional de administração. Foram entrevistados nove indivíduos através da técnica bola de neve, com um roteiro semiestruturado, assim os dados foram coletados, descritos e analisados de forma interpretativa pela autora, com relações entre o referencial teórico abordado.

No que diz respeito a identificar o perfil comportamental de um nômade global e qual sua percepção de mundo, ficou claro com as respostas dos entrevistados que é uma condição em que o próprio sujeito opta por se tornar um nômade, desta forma, ele passa a ser mais observador e a buscar situações no país visitado que possam ser comparadas e melhoradas em seu país de origem. Sua visão de mundo é muito clara, os nômades globais buscam por qualidade de vida, por oportunidades e por um local que seja melhor e agradável para seus moradores.

Em relação a descrever como as experiências no exterior se relacionam com o dia a dia dos acadêmicos e bacharéis em administração, baseado nas respostas dos entrevistados notou-se que as experiências no exterior se relacionam das mais variadas formas com os diferentes sujeitos, através das oportunidades profissionais e acadêmicas, com a forma de pensar e agir em determinadas situações, a maneira como a sociedade como um todo passa a ser questionada a fim de buscar implantar o que foi visto de melhor em outros países, as amizades e vínculos que foram conquistados através da experiência, e acima de tudo a necessidade de buscar conhecer novos lugares e culturas, para desta forma aprender, compreender e disseminar o que mais interessante foi visto.

Sobre descrever como o contato com outras culturas pode agregar na carreira e na visão de mundo dos acadêmicos de administração e bacharéis de administração, as respostas dos 
entrevistados mostraram que muitas empresas ainda não veem a experiência em outras culturas como ferramenta que agrega nos fluxos e atividades da mesma, e os sujeitos da pesquisa deixaram clara a necessidade que o mercado de trabalho tem em abrir oportunidades para que estes profissionais possam aplicar seu conhecimento para a melhoria e desenvolvimento da empresa e do individuo como um todo. Desta forma os entrevistados relataram a importância que as vivências em outras culturas proporcionou para a sua visão de mundo e da sociedade, e nas melhorias pessoais e intelectuais que cada individuo absorveu e desenvolveu.

A partir destes resultados, entende-se que o objetivo da pesquisa foi alcançado, pois as experiências no exterior agregam na carreira e no desenvolvimento da mesma, sempre que o indivíduo se permite absorver e ser modificado através da vivência em outra culturas, e que as empresas podem abrir mais espaço para a introdução das aptidões adquiridas de cada sujeito, mas que cabe ao próprio indivíduo faze-lo ser necessário e mostrar sua importância para a organização.

Entre as limitações deste estudo, destaca-se o tempo que foi necessário para cada pesquisa e a dificuldade de conciliar os horários da autora com o dos entrevistados.

Em relação à continuidade da pesquisas se sugere o foco no departamento de gestão de pessoas e a contratação de colaboradores que possuam experiências em outros países, ou como as empresas veem as vivências em outros países e como buscam aplicar ao dia a dia da organização, também se faz interessante pesquisar se o nível do idioma inglês é aperfeiçoado para o cotidiano das organizações quando aprendido em escolas de idiomas ou quando o profissional aprende com o contato direto com a língua em outros países.

Com base nas discussões entre o referencial abordado no estudo e as entrevistas, observou-se que os nômades globais, 
podem ser o diferencial competitivo da empresa perante suas concorrentes, e desta forma a gestão de pessoas deve estar atenta a este novo profissional, e deixa-lo agir dentro da empresa e mostrar seu diferencial. A sociedade brasileira como um todo tem muito a aprender com as mais variadas práticas em diversos países e a única forma possível de mudar nossa cultura é fazer com que a população tenha conhecimento de outras práticas que possam melhorar a qualidade de vida no Brasil através do seu testemunho e posterior exemplo.

\section{REFERÊNCIAS}

BELSKY, Janet. Desenvolvimento humano: experienciando o ciclo de vida. Porto Alegre: Artmed, 2010. 608 p.

BITENCOURT, Claudia. Gestão contemporânea de pessoas. 2 ed. Porto Alegre: Bookman, 2010. 175 p.

BONIFÁCIO, Taynã Malaspina de Freitas. Geração Y e a busca de sentido na modernidade líquida: eles não são todos iguais e estão mudando as relações de trabalho. Curitiba: Juruá, 2014. 285 p.

CALLIARI, Marcos; MOTTA, Alfredo. Código Y: decifrando a geração que está mudando o país. São Paulo: Évora, 2012. 179 p.

CARVALHO, Antonio Vieira; NASCIMENTO, Luiz Paulo; SERAFIM, Oziléa Clean Gomes. Administração de recursos humanos. 2 ed. São Paulo: Cengage Learning, 2012. 326 p.

CERVO, Amado luiz; BERVIAN, Pedro A. Metodologia Científica . 5. ed. São Paulo: Pearson Prentice Hall, 2002. 242 p.

CHIAVENATO, Idalberto. Gestão de Pessoas. 3. ed. Rio de janeiro: Elsevier, 2010. 579 p.

CRESWELL, John W. Projeto de Pesquisa: Métodos qualitativo, quantitativo e misto. 3 ed. Porto Alegre: Artmed, 2010. 296 p.

DESSLER, Gary. Administração de Recursos Humanos. 3 ed. São Paulo: Pearson Edication do Brasil, 2014. 496 p.

DEWES, João Osvaldo. Amostragem em Bola de Neve e RespondentDrivenSampling: uma descrição dos métodos. 2013. 52 p. 
DUTRA, Joel Souza. Gestão de Pessoas: modelo, processos, tendências e perspectivas. São Paulo: Atlas, 2009. 210 p.

FISCHER, André Luiz; DUTRA, Joel Souza; AMORIM, Wilson Aparecido Costa. Gestão de Pessoas. São Paulo: Atlas, 2009. 77 p.

FRANÇA, Ana Cristina Limongi. Práticas de Recursos Humanos PRH. São Paulo: Atlas, 2011. 93 p.

GIL, Antonio Carlos. Como elaborar Projetos de Pesquisa. 5 ed. São Paulo: Atlas, 2010. 184 p.

HALL, Stuart. A identidade cultural na pós-modernidade. Rio de Janeiro: 2014. 45 p.

IANNI, Octavio. Teorias da Globalização. 13. ed. Rio de Janeiro: Civilização Brasileira, 2006. 271 p.

IORIS, Rafael Rossotto. Culturas em choque: a globalização e os desafios para a convivência multicultural. São Paulo: Annablume, 2007. 41 p.

MARCONI, Marina de Andrade; LAKATOS, Eva Maria. Fundamentos de metodologia científica. 7 ed. São Paulo: Atlas, 2010. 297 p.

MATTEWMAN, Jim. Os novos nômades globais: como será a gestão dessa nova geração de profissionais que desconhece fronteiras e exige cada vez mais das empresas?. São Paulo: Clio Editora, 2012. 255 p.

OLIVEIRA, Sidnei. Geração Y: o nascimento de uma nova versão de líderes. São Paulo: Integrare Editora, 2010. 152 p.

OLIVEIRA, Sidnei. Geração Y: ser potencial ou ser talento? Faça por merecer. São Paulo: Integrare Editora, 2011. 144 p.

OLIVEIRA, Sidnei. Gerações: encontros, desencontros e novas perspectivas. São Paulo: Integrare Editora, 2016. 237 p.

PAPALIA, Diane; OLDS, Sally Wendkos; FELDMAN, Ruth Duskin. Desenvolvimento humano. Porto Alegre: AMGH, 2010. 889 p.

PESSOTTO, Fernando. Temas em educação corporativa: contribuições da psicologia. São Paulo: Vetor, 2014. 154 p.

PUENTE-PALACIOS, Katia; PEIXOTO, Adriano de Lemos Alves. Ferramentas de diagnóstico para organizações e trabalho. Porto Alegre: Artmed, 2015. 330 p. 
ROBBINS, Stephen P. Comportamento Organizacional. Rio de janeiro: Pearson Prentice Hall, 2005. 536 p.

SEIFFERT, Peter Quadros. Gestão humana para o Século XXI: um ensaio na EMBRAER S.A. Rio de janeiro: Qualitymark, 2005. 150 p. SILVA, José Carlos Zanelli; TOLFO, Suzana da Rosa. Processos psicossociais nas organizações e no trabalho. São Paulo: Casa do Psicólogo, 2011. 435 p.

SITE DO ITAMARATY. Contém algumas informações referente a assuntos que competem ao Itamaraty. Disponível em: http://www. brasileirosnomundo.itamaraty.gov.br/noticias/censo-ibge-estima -brasileiros-no-exterior-em-cerca-de-500-mil/impressao - Acesso em 21/09/2015.

STADLER, Adriano. Gestão de pessoas: ferramentas estratégicas de competitividade. Curitiba: InterSaberes, 2014. 190 p.

\section{APÊNDICE A - ROTEIRO DE ENTREVISTA SEMIESTRUTURADO}

Roteiro de entrevista semiestruturado:

- Idade;

- Gênero;

- Estado civil;

- Faixa salarial;

- Quanto gasta mensalmente/contas fixas,

- Quanto guarda mensalmente,

- Área de atuação;

- O que faz no tempo livre? (tanto diariamente, quanto nas férias);

- Onde foram suas vivências fora do país e qual o motivo central de cada viagem?

- Passeio,

- Trabalho,

- Estudo, 
- Se considera um nômade global?

- Em sua percepção, quais características te fazem um nômade global?

- $\quad$ Se não, quais características te impedem de ser um nômade e porque?

- A viagem foi planejada? Quanto tempo de planejamento? Havia um roteiro previamente estabelecido?

- Quais as semelhanças entre as culturas visitadas e a de origem?

- Clima,

- Turismo,

- Câmbio,

- Custo de vida,

- Idioma,

- Ambiente,

- Alimentação,

- Pessoas,

- Mercado de trabalho;

- Diferenças pré e pós viagem

- $\quad$ Timidez

- Idioma

- $\quad$ Estilo

- Ética (ex: sinal vermelho, lixo etc)

- Qual a sua visão em relação ao mercado de trabalho e as vivências no exterior?

- Qual a visão do mercado em relação a experiência no exterior?

- Qual a mudança na vida profissional? (Positiva/negativa).

Conclusão: Faria a experiência novamente? Voltaria ao mesmo destino e procuraria fazer coisas diferentes? Faria as mesmas coisas em outros destinos? 